\title{
Comparison of the Efficiency of Mammography, Contrast-Enhanced Spectral Mammography and Magnetic Resonance Imaging in Female Patients with Multifocal and Multicentral Breast Cancer
}

Katarzyna Steinhof-Radwańska ( $\square$ kasia.steinhof@gmail.com )

Medical University of Silesia: Slaski Uniwersytet Medyczny w Katowicach https://orcid.org/0000-00018127-8829

\section{Andrzej Lorek}

Medical University of Silesia: Slaski Uniwersytet Medyczny w Katowicach

Michał Holecki

Medical University of Silesia: Slaski Uniwersytet Medyczny w Katowicach Anna Barczyk-Gutkowska

Medical University of Silesia: Slaski Uniwersytet Medyczny w Katowicach Anna Grażyńska

Medical University of Silesia: Slaski Uniwersytet Medyczny w Katowicach

\section{Joanna Szczudło-Chraścina}

Oncology Hospital, Bielsko-Biała, Poland

\section{Maciej Kajor}

Medical University of Silesia: Slaski Uniwersytet Medyczny w Katowicach Joanna Lorek

L Rydygiers Voivodship Specialist Hospital: Wojewodzki Szpital Specjalistyczny im L Rydygiera

\section{Oskar Bożek}

Medical University of Silesia: Slaski Uniwersytet Medyczny w Katowicach

Iwona Gisterek

Medical University of Silesia: Slaski Uniwersytet Medyczny w Katowicach

\section{Research article}

Keywords: Breast cancer, contrast-enhanced spectral mammography, mammography, comparative studies, pathology, surgery

Posted Date: February 19th, 2021

DOl: https://doi.org/10.21203/rs.3.rs-217610/v1 
License: (c) (i) This work is licensed under a Creative Commons Attribution 4.0 International License. Read Full License 


\section{Abstract}

Background. The multifocality and multicentrality of breast cancer are the decisive factors influencing surgeon's choice between breast conserving therapy (BCT) and mastectomy.

Methods. The analysis included 71 breast cancer subjects out of 727 patients initially operated on due to breast cancer from January 2013 to April 2019. MG, CESM and MRI were compared with one another in terms of the presence of multifocal/multicentral breast cancers (MFMCC), and assessed for compliance with the postoperative histopathological examination (HP), by calculating the sensitivity and specificity for each of the methods. The aim was to examine which histopathological types of breast cancer were characterised by a more frequent occurrence of MFMCC in relation to the general number of cancers identified in HP. It was also analysed if MRI and CESM changed the planned scope of surgery.

Results. The sensitivity of MG in detecting MFMCC was $42.1 \%(26.31$ - 59.18), its specificity, positive (PPV) and negative predictive value (NPV) were 93.9\% (79.77 - 99.26), 88.8\% and 58.5\%, respectively. For CESM, the sensitivity was $84.2 \%$ (68.75 - 93.98), its specificity, PVV and NPV were $90.9 \%$ (75.67 98.08), $91.4 \%$, and $83.3 \%$, respectively. For MRI, all above mentioned parameters were higher, as follow: level of sensitivity $94.7 \%$ (82.25 - 99.36), specificity - 93.9\% (79.77 - 99.26), PPV - 94.7\%, and NPV $93.9 \%$. In 38 out of 71 patients (53.5\%), histopathological examination (HP) confirmed the multifocal and multicentral nature of the breast cancer.

\section{Conclusion}

1. In patients with multifocal/multicentral breast cancer both CESM and MRI are highly sensitive in detection of additional cancer foci.

2. Both CESM and MRI change the extent of surgical intervention in every fourth patient.

Trial registration: retrospectively registered

\section{Background}

Breast cancer is both the most common malignancy and the leading cause of cancer death in women worldwide [1]. The choice of local and systemic treatment for breast cancer depends on both the histological type and grading, the progression of the primary tumour, the status of regional lymph nodes, the presence of metastases and concomitant diseases, as well as the patient's individual preferences [2, 3]. The multifocality and multicentrality of neoplastic lesions are the decisive factors influencing surgeon's choice between breast conserving therapy (BCT) and mastectomy [4,5]. Breast cancers are defined as 'multifocal' when two or more cancer foci are present within the same quadrant, while 'multicentral' - when the foci occur in different quadrants [6, 7]. In imaging diagnostics, a neoplastic process is identified as 'multifocal' when the distance between the lesions in lower than or equal to $5 \mathrm{~cm}$, while 'multicentral' - when this distance is higher than $5 \mathrm{~cm}$ [8]. 
Of the many imaging methods available, mammography is the basic choice for detecting neoplastic foci in breasts, since it is cheap, widely accessible and reproducible. The sensitivity of digital mammography (MG) depends on breast structure and significantly decreases, to reach approx. 60\%, in breasts with a predominantly glandular tissue $[9,10]$.

Magnetic resonance imaging (MRI) mammography, extended with diffusion imaging (DWI/ADC) is a test with a high level of sensitivity and specificity (over $85 \%$ ) $[11,12,13]$; however, its limitations are worth noting either. They include false-positive results, which may result in more aggressive management and treatment than necessary, hence the role of breast MRI in the pre-operative assessment of breast cancer is currently under discussion. Additionally, microcalcifications are not visible and the acquisition time is long, ranging approximately 20 and 30 minutes.

In opposite to mammography, that underestimates the tumour size which can result in incomplete resection, $\mathrm{MRI}$ is more accurate in imaging the local extent of breast cancer, tumour size, and carcinoma location. Moreover, some carcinomas and foci are seen only on breast MRI scans (14-18).

Contrast-enhanced spectral mammography (CESM) is a new technique, intensively developed in the last few years and accepted by the FDA for clinical use in the U.S. in 2011. This method, like MRI, is based on imaging of tumour neoangiogenesis by use of contrast agent (chelated iodine-based X-ray contrast agent) $(19,20)$. Contrast-enhanced spectral mammography is based on the double-energy technology that capitalises on the inherent difference in x-ray attenuation of breast tissue and iodine. It provides morphological information available in conventional mammography, and additionally makes it possible to visualise breast areas that exhibit enhanced uptake of the contrast agent most commonly related to neoangiogenesis, as is the case with breast magnetic resonance imaging (MRI). CESM uses x-rays just like conventional mammography does. The average glandular dose (AGD) for a low-energy image is equal to one conventional mammography, while for a high-energy image - it is approximately $20 \%$ of the dose from one conventional mammography. The sensitivity of CESM is over $90 \%$ [21, 22]. Only a few studies have evaluated bilateral contrast-enhanced spectral mammography as an alternative to MR imaging, citing its similar ability to depict lesion morphologic features and perfusion characteristics while doing so at lower cost and with faster image acquisition, equal sensitivity in the detection of index cancers and superior specificity $(23,24,25)$.

It should be noted that multicentral carcinomas are more common in young patients or in perimenopausal women with large tumours $(>5 \mathrm{~cm})$ and high-density fibroglandular parenchyma, women with a family history of breast cancer and in cases of invasive lobular carcinoma [26]. That is why breast cancer detection requires a multimodal approach and the radiologist must apply several imaging modalities accordingly.

For the purposes of the present study multifocal and multicentral cancers were commonly defined as MFMCC. 
The objective of the paper was to assess the usefulness of MG, CESM and MRI in women diagnosed with breast cancer before qualifying for surgical intervention in order to visualise other (additional) cancer foci. Additionally, we wanted to evaluate the difference of surgical decisions made upon application of CESM and MRI versus those based on MG.

\section{Methods}

We did retrospective analysis of 727 medical records of patients with initially operable breast cancer, who had been operated on from January 2013 to April 2019 at the Department of Oncological Surgery, University Clinical Center prof. K. Gibiński of the Medical University of Silesia in Katowice, Poland.

The inclusion criteria for the study included diagnosed breast cancer (based on a core needle biopsy) and a complete set of imaging examinations before the procedure consisted of digital mammography, contrast-enhanced spectral mammography and magnetic resonance imaging. 71 out of 727 breast cancer patients were included into the analysis. In our centre, MRI examination was not performed in each breast cancer patient that was in line with the current recommendations of EUSOMA (The European Society of Breast Cancer Specialists). According to those recommendations MRI examination is performed in patients diagnosed with lobular cancer and patients under the age of 60 years who experienced a difference in the tumour's size $>1 \mathrm{~cm}$ between MG and USG, and when this difference can determine the type of surgical procedure.

After completing the diagnostics, the final therapeutic decision was made on the basis of an arrangement of interdisciplinary case conference (of the $\mathrm{BCU}$ ) with the participation of the patient and a team of specialists, including oncological surgeon, a clinical oncologist, a radiotherapist, a radiologist, and a pathomorphologist. The patient was able to ask questions and expressed informed consent to the proposed treatment. Ethical committee approval was not required due to the retrospective nature of the study and the lack of criterion of medical experiment (Bioetics Commission Decision $\mathrm{PCN} / 0022 / \mathrm{KB} / 189 / 20$ ). All the test procedures were carried out in compliance with the ethical principles of the 1964 Helsinki Declaration and its subsequent amendments.

Imaging procedures

All the CESM examinations were performed in our centre while MG examinations we performed on an outpatient's basis (in most cases as a screening test), and then checked by two consultant radiologists from our centre. Before qualifying for CESM and MRI, all patients completed a questionnaire which was the basis for disqualifying those women with pregnancy or allergy to contrast agents (both the iodinebased contrast used in CESM and the gadolinium-based contrast agents used in MRI). eGFR less than 30 $\mathrm{mL} / \mathrm{min}$ excluded patients from the study.

\section{CESM}


As in the previous papers $(22,47)$, all CESM examinations were carried out with a digital mammography device dedicated to perform dual-energy CESM acquisitions (SenoBright, GE Healthcare). An intravenous injection of $1.5 \mathrm{ml} / \mathrm{kg}$ of body mass of non-ionic contrast agent was performed using a power injector at a rate of $3 \mathrm{ml} / \mathrm{s}$ with a bolus chaser of $30 \mathrm{ml}$ of saline. In CESM mode, the device automatically performed a pair of exposures (low- and high-energy) in each view. Specific image processing of lowenergy and high-energy images was done to obtain subtraction images to highlight contrast enhancement and suppress structured noise due to fibroglandular breast tissue [17]. The total examination time was usually 10 minutes. After examination, the patients were observed for approx. 30 minutes for any adverse reactions that may occur after administration of the contrast agent.

\section{MRI Protocol}

All contrast-enhanced MRI examinations were performed with a 1.5T MRI system. All patients underwent MRI examinations in the prone position using a dedicated 4-channel breast coil. Our protocol in the transverse plane included: T1-weighted spin-echo (TSE) sequence, T2-weighted TSE, and T2-weighted TSE with fat saturation (thickness of the layer was $3 \mathrm{~mm}$ ), echo-planar diffusion-weighted imaging with apparent diffusion coefficient (thickness of the layer was $5 \mathrm{~mm}$ ), and Vibrant - dynamic sequence with fat saturation was performed before the administration of contrast agent, followed by 6 repetitions of the same sequence. Duration of each post-contrast acquisition was about 1 minute, depending on breast size, the thickness of the layer was $2 \mathrm{~mm}$. Post-contrast dynamic MR images were acquired after administration of $0.1 \mathrm{mmol} / \mathrm{kg}$ of body mass of gadolinium contrast agent.

The MG, CESM and MR images were assessed on the basis of the BI-RADS scale (Breast ImagingReporting and Data System, according to ACR BI-RADS Atlas ${ }^{\circledR}$ 5th Edition) (27). A lesion that had already been confirmed to be cancerous in core-needle biopsy was classified as BI-RADS 6, while additional foci suspected of multifocal or multicentric neoplastic process were classified as BI-RADS 4 or BI-RADS 5.

(Figs. 1a,b,c)

Surgical treatment

A total of 727 surgical interventions were performed, involving the following procedures:

- Madden type radical mastectomy - $156(21.4 \%)$

- wide local excision (WLE) with sentinel lymph node biopsy (SLNB) - 290 (39.8\%)

- wide local excision (WLE) with axillary lymph node dissection (ALND) - 52 (7.1\%)

- total (simple) mastectomy - $15(2 \%)$

- total (simple) mastectomy with SLNB - 135 (18.5\%)

- subcutaneous mastectomy with reconstruction with SLNB - 21 (2.8\%)

- subcutaneous mastectomy with reconstruction with SLNB - 19 (2.6\%)

\section{- WLE - 39 (5.3\%)}


The number of procedures performed in the group of 71 patients under analysis is as follows:

40 (56\%) breast-conserving surgeries:

- 12 (16.9\%) WLE with ALND;

- 25 (35.2\%) WLE with SLNB;

\section{- 3 (4.2\%) WLE}

31 (44\%) different types of mastectomy.

Histopathological examination

As in our previous papers $(22,47)$, the histopathological examination was performed in the Histopathology Laboratory of our centre by 2 pathologists with extensive experience (of more than 15 years) in breast cancer diagnostics. The greatest dimension of the tumour necessary for determining the T descriptor in the pTNM classification, besides the macroscopic measurement, was verified histopathologically by means of a microscope and the cellSens Dimension ${ }^{\circledR}$ software by Olimpus from 2013. Tumours up to $2 \mathrm{~cm}$ were excised in whole, serially, on a cross-sectional basis with a margin of 0.2 to $0.4 \mathrm{~cm}$ and embedded in a paraffin block, after each cross section. Tumours measuring over $2 \mathrm{~cm}$, not fitting within a single paraffin block, were divided into 2 or more parts by making parallel cuts of the lesion. Next, they were marked in pairs with ink of the same colour and the individual layers were given numbers to allow for restoring the entire largest section of the tumour. The $T$ value of the tumour was the total of the parallel measurements of the particular parts of the lesion. The tumours were defined as MFMCC if two lesions were separated by at least $5 \mathrm{~mm}$ of healthy tissue. All the additional neoplastic foci diagnosed histopathologically had their histological features defined, including the tumour's size, type and malignancy level. The study included infiltrating cancers and in-situ cancers.

Data Analysis and Statistical Method

The analysis included the results of 71 patients selected according to the above-mentioned inclusion criteria. Patients' age distribution was analysed and tested for normality using the Kołmogorov-Smirnov test. The average, minimum and maximum values in the sample as well as standard deviation were determined for the variable studied. The subsequent part of the statistical analysis involved construction of contingency tables for the results of MFMCC detectability for each of the diagnostic methods under analysis, compared with HP. The analysis of these tables served as the basis for calculating the values of sensitivity, specificity, negative predictive value (NPV) and positive predictive value (PPV) for each of the methods (MG, CESM, and MRI). The $95 \%$ confidence intervals for the calculated sensitivity and specificity values were determined on the basis of the Clopper-Pearson estimation method, using the $Z$ test for a single proportion. Next, graphs of ROC curves were drawn up for each of the methods, and the values of the AUC field under the curves were calculated and compared with one another. Standard errors were also calculated for half-AUC. The significance limit for the calculations was established at $p=0.05 \mathrm{~A}$ 
quantitative summary was also prepared for the histopathological types of cancers, and the level of their detectability was determined for the diagnostic methods under analysis. The diagnostic results in the methods under analysis served as the basis for determining the rate of decision change in the treatment procedure. The data were analysed using an Excel spreadsheet and the Statistica software.

\section{Results}

Patients' median age was equal to 65 years (with the minimum age in the sample being 29 years and the maximum - 91 years). The consistency of histopathological examination with the results of digital mammography (MG), contrast-enhanced spectral mammography (CESM), and magnetic resonance imaging (MRI) in terms of detecting MFMCC are presented in Table 1.

Table 1

Compliance of MG, CESM and MRI in terms of detecting multifocal-multicentral breast cancers (MFMCC), confirmed in postoperative histopathological examination (HP)

\begin{tabular}{|c|c|c|c|c|}
\hline \multicolumn{5}{|c|}{ Assessment } \\
\hline & & $\mathrm{HP}$ & $\mathrm{HP}$ & \\
\hline & & multifocal & unifocal & \\
\hline \multirow[t]{3}{*}{ MG } & multifocal & 16 & 2 & $\begin{array}{l}\text { PPV } 88.8 \%(95 \% \mathrm{Cl} \\
: 65.29-98.62)\end{array}$ \\
\hline & unifocal & 22 & 31 & $\begin{array}{l}\text { NPV } 58.5 \%(95 \% \mathrm{Cl} \\
: 44.13-71.86)\end{array}$ \\
\hline & & $\begin{array}{l}\text { Sensitivity } 42.1 \%(95 \% \\
\text { Cl: } 26.31-59.18)\end{array}$ & $\begin{array}{l}\text { Specificity } 93.9 \% \\
\text { (95\% Cl:79.77-99.26) }\end{array}$ & \\
\hline \multirow[t]{3}{*}{ CESM } & multifocal & 32 & 3 & $\begin{array}{l}\text { PPV } 91.4 \%(95 \% \\
\text { Cl:76.94-98.2) }\end{array}$ \\
\hline & unifocal & 6 & 30 & $\begin{array}{l}\text { NPV } 83.3 \%(95 \% \\
\text { Cl:67.19-93.63) }\end{array}$ \\
\hline & & $\begin{array}{l}\text { Sensitivity } 84.2 \%(95 \% \\
\text { Cl:68.75-93.98) }\end{array}$ & $\begin{array}{l}\text { Specificity } 90.9 \% \\
\text { (95\% Cl:75.67-98.08) }\end{array}$ & \\
\hline \multirow[t]{3}{*}{ MRI } & multifocal & 36 & 2 & $\begin{array}{l}\text { PPV } 94.7 \%(95 \% \\
\text { Cl:82.25-99.36) }\end{array}$ \\
\hline & unifocal & 2 & 31 & $\begin{array}{l}\text { NPV } 93.9 \%(95 \% \\
\text { Cl:79.77-99.26) }\end{array}$ \\
\hline & & $\begin{array}{l}\text { Sensitivity } 94.7 \%(95 \% \\
\text { Cl: } 82.25-99.36)\end{array}$ & $\begin{array}{l}\text { Specificity } 93.9 \% \\
\text { (95\% Cl:79.77-99.26) }\end{array}$ & \\
\hline
\end{tabular}

The sensitivity of MG in detecting MFMCC was $42.1 \%$ (26.31-59.18), its specificity, positive (PPV) and negative predictive value (NPV) were $93.9 \%$ (79.77-99.26), 88.8\% and 58.5\%, respectively. For CESM, the sensitivity was $84.2 \%$ (68.75-93.98), its specificity, PVV and NPV were 90.9\% (75.67-98.08), 91.4\%, and 
$83.3 \%$, respectively. For MRI, all above mentioned parameters were higher, as follow: level of sensitivity 94.7\% (82.25-99.36), specificity - 93.9\% (79.77-99.26), PPV - 94.7\%, and NPV - 93.9\%.

The ROC curve was determined based on MG, CESM and MRI (Figs. 2a, 2b, 2c).

Results of verification which histopathological types of cancers (in absolute numbers and in percentage values of the total incidence) are detected as multifocal in comparable examination techniques are presented in Table 2.

Table 2

The histopathological types of cancer detected as multifocal/multicentral breast carcinoma (MFMCC)

\begin{tabular}{|c|c|c|c|c|c|c|}
\hline $\begin{array}{l}\text { Breast } \\
\text { cancers }\end{array}$ & $\begin{array}{l}\text { All } \\
\text { occurrences }\end{array}$ & $\begin{array}{l}\text { Neoplastic lesions of } \\
\text { multifocal/multicentral } \\
\text { nature (MFMCC) }\end{array}$ & MG & CESM & MR & $\mathrm{HP}$ \\
\hline NST & $7(9.86 \%)$ & $6 / 7$ (85.71\%) & $\begin{array}{l}1 \\
(1.41 \%)\end{array}$ & $\begin{array}{l}6 \\
(8.45 \%)\end{array}$ & $\begin{array}{l}5 \\
\text { (7.04\%) }\end{array}$ & $\begin{array}{l}6 \\
(8.45 \%)\end{array}$ \\
\hline $\begin{array}{l}\text { Ca } \\
\text { Lobulare }\end{array}$ & 51 (71.83\%) & $24 / 51(47.05 \%)$ & $\begin{array}{l}13 \\
(18.31 \%)\end{array}$ & $\begin{array}{l}24 \\
(33 / 8 \%)\end{array}$ & $\begin{array}{l}25 \\
(35.21 \%)\end{array}$ & $\begin{array}{l}24 \\
(33.8 \%)\end{array}$ \\
\hline $\begin{array}{l}\text { Special } \\
\text { subtype }\end{array}$ & $1(1.41 \%)$ & $1 / 1(100 \%)$ & & $\begin{array}{l}1 \\
(1.4 \%)\end{array}$ & $\begin{array}{l}1 \\
(1.41 \%)\end{array}$ & $\begin{array}{l}1 \\
(1.41 \%)\end{array}$ \\
\hline DCIS HG & $5(7.04 \%)$ & 4/5 (80\%) & $\begin{array}{l}3 \\
(4.23 \%)\end{array}$ & $\begin{array}{l}3 \\
(4.23 \%)\end{array}$ & $\begin{array}{l}4 \\
(5.63 \%)\end{array}$ & $\begin{array}{l}4 \\
(5.63 \%)\end{array}$ \\
\hline $\begin{array}{l}\text { Ca } \\
\text { ducto- } \\
\text { lobulare }\end{array}$ & $7(9.86 \%)$ & $3 / 7$ (42.85\%) & $\begin{array}{l}1 \\
(1.41 \%)\end{array}$ & $\begin{array}{l}1 \\
(1.41 \%)\end{array}$ & $\begin{array}{l}3 \\
(4.23 \%)\end{array}$ & $\begin{array}{l}3 \\
(4.23 \%)\end{array}$ \\
\hline Total & 71 (100\%) & $53.52 \%$ & 18 & 35 & 38 & $\begin{array}{l}38 \\
(53.52 \%)\end{array}$ \\
\hline
\end{tabular}

The analysis involved the number of changes in the extent of conserving treatment into different mastectomies upon identification of multifocal-multicentral breast cancers (MFMCC) in CESM and MR (Table 3). 
Table 3

Changes in surgery extent upon identification of multifocal-multicentral breast cancers (MFMCC) in CESM and MR

\begin{tabular}{|lllll|}
\hline $\begin{array}{l}\text { Types of } \\
\text { surgeries }\end{array}$ & $\begin{array}{l}\text { Planned } \\
\text { surgeries } \\
\text { based } \\
\text { on MG }\end{array}$ & $\begin{array}{l}\text { Surgeries } \\
\text { following } \\
\text { MFMCC } \\
\text { visualisation } \\
\text { in CESM } \\
\text { and MR }\end{array}$ & $\begin{array}{l}\text { Number } \\
\text { of changes in } \\
\text { surgery extent into } \\
\text { different } \\
\text { mastectomies }\end{array}$ & $\begin{array}{l}\text { Local radicalisation in the } \\
\text { group of patients on } \\
\text { conserving treatment with } \\
\text { MFMCC. }\end{array}$ \\
\hline $\begin{array}{l}\text { Different } \\
\text { mastectomies }\end{array}$ & 18 & 31 & $13(72.2 \%)$ & 0 \\
\hline WLE + ALND & 14 & 12 & $2(14.2 \%)$ & 1 \\
\hline WLE & 5 & 3 & $2(40.0 \%)$ & 0 \\
\hline WLE + SLNB & 34 & 25 & $9(26.4 \%)$ & 1 \\
\hline In total & 71 & 71 & $26(36.6 \%)$ & 2 \\
\hline WLE, wide local excision, SLNB, sentinal lymph node biopsy & \\
\hline
\end{tabular}

Based on the MG performed, it was planned to conduct 53 conserving surgeries (WLE) in the study group. Upon visualising 13 cases of MFMCC following CESM and MRI, a decision was taken to conduct different types of mastectomy. The decision change rate was $13 / 53=24 \%$.

In those 13 patients, the HP results confirmed MFMCC in 12 (92.3\%) cases. In 1 (7.6\%) case, the results obtained were false positive (the preoperative core needle biopsy revealed atypical ductal hyperplasia). In the group of MFMCC patients on conserving therapy, there were positive margins (R1 resection) in 2 cases in HP examination, which required local radicalisation.

\section{Discussion}

Breast cancer is the most common malignancy affecting women both in Poland and worldwide. A multifocal and/or multicentral neoplastic process is defined in approx. $5-12 \%$ of female patients $(28,29,30)$. In our analysis, multifocality and multicentrality of the lesions were confirmed in 38 subjects (38/71, which is $53.5 \%$ of all the examined ones). The obtained results are extremely alarming, but unfortunately coincide with the results of other researchers who noticed the same trend at a similar time. Tot and colleagues found that $40 \%$ of breast carcinomas had a simple (unifocal) subgross morphology, while $60 \%$ had a complex morphology presenting with multifocal or diffuse components (31).

Surgery plays a fundamental role in treatment of breast cancer. According to the Senologic International Society (SIS) recommendations, approximately $70-80 \%$ of early breast cancer cases should be referred 
for breast-conserving therapy (32). However, it should be noted that accurate preoperative knowledge about the extent, size and location of neoplastic lesions is a necessary condition for proper surgical intervention.

The basic examinations for proper treatment qualification include mammography and ultrasonography (USG). The sensitivity of digital mammography in detecting multiple breast lesions depends on breast structure. The greater the content of glandular tissue, the lower sensitivity of mammography, which does not exceed approx. $60 \%$ in breasts with a predominance of glandular tissue. The insufficient sensitivity of mammography and ultrasonography in detecting additional breast cancer foci was raised by Bozzini et al. in 2008. The authors determined the sensitivity of mammography and ultrasonography for assessing additional cancer foci at the level of $45.5 \%$ and $52.9 \%$, respectively (33). Unfortunately, despite the passage of time and the technological development, our results are similarly alarming- mammography failed to detect over $50 \%$ of additional cancer foci. In our analysis, the sensitivity of MG for detecting additional cancer foci was $42 \%$. It seems that the glandular and adipose-gland structures of the breast and the tumor density similar to that of the surrounding glandular tissue resulted in such a low sensitivity in detecting additional cancer foci. tiDuring the re-evaluation there was no significant increase in the MG sensitivity. Similar results were presented by Bozzini et al. who found that the second-look MG assessment did not significantly increase the number of identified additional cancer foci [33].

After breast-conserving surgical therapy postoperative radiotherapy prevents recurrence of the disease both in terms of local recurrence and the formation of further foci of the malignant process. For about a decade, there has been a tendency to limit the irradiated area according to the APBI strategy (accelerated partial breast irradiation). Currently, according to ASTRO (American Society for Radiation Oncology) guidelines, such therapeutic methods are acceptable in patients over the age of 50 years, with postoperative margins following tumour resection measuring $>2 \mathrm{~mm}$ and staging Tis or T1N0. However, due to the possibility of leaving additional cancer foci outside the therapeutic area, a small minority of patients continue to receive this technique of radiation therapy, which significantly reduces radiationinduced skin reactions $(34,35,36)$.

As it is almost impossible to exclude the presence of additional cancer foci on the basis of either mammography or ultrasonography it seems reasonable to use imaging techniques with higher sensitivity. Magnetic resonance imaging (MRI) has documented higher sensitivity in detecting neoplastic lesions than both digital mammography (MG) and ultrasound (USG) [37, 38]. It was documented that even as much as $14 \%-16 \%$ of tumours visible on MRI may remain invisible on MG $[39,40]$.

In our analysis, the use of MRI in preoperative diagnostics resulted in a change in the treatment regimen in $24 \%$ of subjects. Our results are consistent with data obtained by other researchers - performing an MRI examination in breast cancer patients results in modifications of the treatment method in every fifth patient $[41,42]$. Despite the evidence of frequent change of therapeutic decision after MRI examination in patients with breast cancer, this method still remains controversial in this group of patients. Indeed, in a multicenter clinical trial, the authors of "COMICE" did not prove the unequivocal benefits of using MRI in 
the diagnosis of breast cancer. The patients in COMICE trial were mostly post-menopausal women with ACR BI-RADS group 2 and only $9 \%$ of them had the luminal type breast cancer. The authors showed a higher percentage of multifocal and multicenter tumors in the MRI group, but this difference was neither analysed nor discussed. Moreover, most of reoperations were performed due to the non-radical nature of previously performed ones. [43]. The authors of MONET trial did not also demonstrate any benefits of using preoperative MRI examination. This was probably because the study was aimed the diagnosis of non-palpable breast tumours in which there are small and very diverse clinical stages of cancers. Of note, patients after MRI examination were characterized by increased re-excision rate [44]. It should be noted, however, that the COMICE trial included centres without the possibility MRI-guided biopsy. As a result, some of the patients underwent surgery without prior histopathological assessment of the visible foci. In addition, the radiologists' experience was much less than it is now, as this method was relatively new. Finally, there was no standard MRI protocol for all centres.

In our analysis, the sensitivity of MRI for detecting additional cancer foci was $94.7 \%$. The decision to change the scope of surgery from conserving treatment to mastectomy was made in every fourth women (24\%), after core needle biopsy of the revealed lesion. It is worth noting that the radiologists in our centre have at least 10 years' experience in both performing and evaluating MRI, moreover all suspected foci were additionally verified by core needle biopsy.

According to EUSOMA guidelines by (Magnetic resonance imaging of the breast: Recommendations from the EUSOMA working group) the MRI examination is currently recommended in the following clinical situations: a newly diagnosed lobular breast carcinoma confirmed by breast biopsy, patients with genetically detected mutation, and patients under the age of 60 years who manifest discrepancy of more than $1 \mathrm{~cm}$ in the tumour's size between MG and USG [45]. On the contrary, there is no recommendation for the use of CESM. It seems to be incomprehensible, as contrast-enhanced spectral mammography is highly sensitive in detecting breast cancer - comparable to that of MRI. Moreover, the tumours dimensions in CESM correlate well with histopathological examinations, the cost of CESM is lower than that of MRI, and finally, the time needed to perform and interpret the results is less than with MRI [46, 47]. In our CESM analysis, 3 patients had false-positive results, but in MRI examination there were 2 false positive ones. However, it should be noted that a preoperative core needle biopsy revealed atypical intraductal hyperplasia in these cases.

The use of CESM and MRI allows to achieve better results in the diagnosis of MFMCC compared to MG and significantly influences the surgical decisions made. Accurate breast imaging and visualisation of additional cancer foci may, in the future, reduce the volume of postoperative breast radiotherapy after conserving treatment in a much larger group of patients. Such a procedure will allow to reduce the number of complications in patients, and also significantly reduce the treatment costs.

Our study has some limitations, first is associated with relatively small group of patients. This is due to the fact that not all patients diagnosed with breast cancer and qualified for surgery had an MRI scan. MRI was only used in those patients who met EUSOMA recommendations. 


\section{Conclusions}

In patients with multifocal/multicentral breast cancer both CESM and MRI are highly sensitive in detection of additional cancer foci.

Both CESM and MRI change the extent of surgical intervention in every fourth patient.

\section{Abbreviations}

breast conserving therapy $(\mathrm{BCT})$

multifocal/multicentral breast cancers (MFMCC)

histopathological examination (HP)

positive (PPV) and negative predictive value (NPV)

digital mammography (MG)

Magnetic resonance imaging (MRI)

Contrast-enhanced spectral mammography (CESM)

The average glandular dose (AGD)

EUSOMA (The European Society of Breast Cancer Specialists)

BI-RADS scale (Breast Imaging-Reporting and Data System, according to ACR BI-RADS Atlas ${ }^{\circledR}$ 5th Edition)

wide local excision (WLE) with sentinel lymph node biopsy (SLNB)

axillary lymph node dissection (ALND)

ASTRO (American Society for Radiation Oncology)

craniocaudal $(C C)$

mediolateral oblique $(M L O)$

\section{Declarations}

\section{CONTRIBUTION STATEMENT}

KSR and AL conceived the idea for study. KSR, AL, ABG contributed to the design of the research. 
$K S R, A J, A G$, IG conceived the idea for the analysis.

$A J, J L, A B G, J S C$ were involved in data collection.

KSR, ABG, MH, AG, IG analyzed the data.

KSR, AJ, MH, ABG, OB, IG drafted the manuscript.

All authors edited and approved the final version of the manuscript.

\section{Ethics approval and consent to participate}

Due to the retrospective nature of this study, the local ethics committee of the Medical University of Silesia repealed the requirement of informed consent (decision number PCN/0022/KB/189/20).

\section{Consent for publication}

Not applicable

\section{Availability of data and materials}

The datasets during and/or analysed during the current study available from the corresponding author on reasonable request.

\section{Competing interests}

The authors declare that they have no competing interests

\section{Funding}

No funding was received

\section{Acknowledgements}

Not applicable

\section{References}

1. International Agency for Research on Cancer. GLOBOCAN 2018. Available from: http://globocan.iarc.fr [Google Scholar]

2. Curigliano G, Burstein HJ, Winer EP, et al. Panel Members of the St. Gallen International Expert Consensus on the Primary Therapy of Early Breast Cancer 2017, St. Gallen International Expert Consensus on the Primary Therapy of Early Breast Cancer 2017. De-escalating and escalating treatments for early-stage breast cancer: the St. Gallen International Expert Consensus Conference 
on the Primary Therapy of Early Breast Cancer 2017. Ann Oncol. 2017; 28(8): 1700-1712, doi: 10.1093/annonc/mdx308, indexed in Pubmed: 28838210

3. 3. Garcia-Etienne CA, Tomatis $M$, Heil J, et al. Mastectomy trends for early-stage breast cancer: a report from the EUSOMA multi-institutional European database. Eur J Cancer. 2012;48(13):19471956.

4. Veronesi U, Cascinelli N, Mariani L, et al. Twenty-year follow-up of a randomized study comparing breast-conserving surgery with radical mastectomy for early breast cancer. N Engl J Med. 2002; 347(16): 1227-1232, doi: 10.1056/NEJMoa020989, indexed in Pubmed: 12393819

5. Mahmood U, Hanlon AL, Koshy M, et al. Increasing national mastectomy rates for the treatment of early stage breast cancer [published online November 8, 2012]. Ann Surg Oncol. doi:10.1245/s10434012-2732-5.

6. Syed A. Hoda MD, Edi Brogi MD, PHD, Frederick C et al Rosen MD Rosen PP: Rosen's Breast Pathology. ISBN/ISSN 9781451176537 March 6, 2014

7. Milim Kim, Hyun Jeong Kim, Yul Ri Chung et al .Microinvasive Carcinoma versus Ductal Carcinoma In Situ: A Comparison of Clinicopathological Features and Clinical Outcomes.J Breast Cancer. 2018 Jun;21(2):197-205. English.Published online June 20, 2018. https://doi.org/10.4048/jbc.2018.21.2.197

8. Sardanelli F, Giuseppetti GM, Panizza P et al : Italian Trial for Breast MR in Multifocal/Multicentric Cancer. Sensitivity of MRI versus mammography for detecting foci of multifocal, multicentric breast cancer in Fatty and dense breasts using the whole-breast pathologic examination as a gold standard. AJR Am J Roentgenol. 2004, 183: 1149-1157.

9. 9. A L Mousa DS, Ryan EA, Mello-Thoms C, Brennan PC. What effect does mammographic breast density have on lesion detection in digital mammography?. Clin Radiol. 2014;69(4):333-341. doi:10.1016/j.crad.2013.11.014

10. Francesco Sardanelli, Gian M. Giuseppetti, Pietro Panizza Massimo Bazzocchi. MR in Multifocal/Multicentric Cancer Sensitivity of MRI Versus Mammography for Detecting Foci of Multifocal, Multicentric Breast Cancer in Fatty and Dense Breasts Using the Whole-Breast Pathologic Examination as a Gold Standard Cancer Imaging. 2008; 8(Spec Iss A): S6-S9.

11. Azab EAlbrahim ME. Diffusion weighted (DW) MRI role in characterization of breast lesions using absolute and normalized ADC values. Egyptian Journal of Radiology and Nuclear Medicine 2018; 49: 564-570.

12. Yadav $P$ Chauhan S. Effectivity of combined diffusion-weighted imaging and contrast-enhanced MRI in malignant and benign breast lesions. Pol J Radiol 2018; 83: e82-e93.

13. Yılmaz ESarı OYılmaz Aet al. Diffusion-weighted imaging for the discrimination of benign and malignant breast masses; utility of ADC and relative ADC. J Belg Soc Radiol 2018; 102: 24.

14. Mann RM, Veltman J, Barentsz JO, et al. The value of MRI compared to mammography in the assessment of tumour extent in invasive lobular carcinoma of the breast, Eur J Surg Oncol, 2008;34:135-42. 
15. Chiara Iacconi , Lanie Galman, Junting Zheng et al Multicentric Cancer Detected at Breast MR Imaging and Not at Mammography: Important or Not? Published Online:Nov 2015https://doi.org/10.1148/radiol.2015150796

16. Drew PJ, Chatterjee S, Turnbull LW, et al.Dynamic contrast enhanced magnetic resonance imaging of the breast is superior to triple assessment for the pre-operative detection of multifocal breast cancer, Ann Surg Oncol, 1999;6:599-603.

17. Al-Hallaq HA, Mell LK, Bradley JA, et al. Magnetic resonance imaging identifies multifocal and multicentric disease in breast cancer patients who are eligible for partial breast irradiation, Cancer, 2008;113:2408-14.

18. Mann RM, Hoogeveen YL, Blickman JG, Boetes C, MRI compared to conventional diagnostic work-up in the detection and evaluation of invasive lobular carcinoma of the breast: a review of existing literature, Breast Cancer Res Treat, 2008;107:1-14.

19. Daniaux M, De Zordo, TSantner Wet al. Dual-energy contrast-enhanced spectral mammography (CESM). Arch Gynecol Obstet 2015; 292: 739-747.

20. Bhimani CMatta DRoth RGet al. Contrast-enhanced spectral mammography: technique, indications, and clinical applications. Acad Radiol 2017; 24: 84-88.

21. 21. Omnia Mokhtar, Sheryhan Mahmoud. Can contrast enhanced mammography solve the problem of dense breast lesions? The Egyptian Journal of Radiology and Nuclear MedicineVolume 45, Issue 3, September 2014, Pages 1043-1052

22. Katarzyna Steinhof-Radwańska , Anna Grażyńska, Anna Barczyk-Gutkowska et al. The new method, the old problem - role of contrast-enhanced spectral mammography in the diagnosis of breast cancer among Polish women. J Radiol 2020; 85: e381-e386 DOI:

https://doi.org/10.5114/pjr.2020.97941

23. Jochelson MS, Dershaw DD, Sung JS et al. Bilateral contrast-enhanced dual-energy digital mammography: feasibility and comparison with conventional digital mammography and MR imaging in women with known breast carcinoma. Radiology 2013;266(3):743-751. Link, Google Scholar

24. 24. Fallenberg EM, Dromain C, Diekmann F et al. Contrast-enhanced spectral mammography versus MRI: initial results in the detection of breast cancer and assessment of tumour size. Eur Radiol 2014;24(1):256-264. Crossref, Medline, Google Scholar

25. 25. Stephanie A. Lee-Felker, Leena Tekchandani, Mariam Thomas et al. Newly Diagnosed Breast Cancer: Comparison of Contrast-enhanced Spectral Mammography and Breast MR Imaging in the Evaluation of Extent of Disease Jun 26 2017https://doi.org/10.1148/radiol.2017161592

26. Ellis IO, Schnitt SJ, Sastre-Garau X, et al. Invasive breast carcinoma. In: Tavassoli FA, Deville P (eds), World Health Organization Classification of Tumours. Pathology and Genetics of Tumours of the Breast and Female Genital Organs, 1st edn, Lyon: IARC Press, 2003.

27. ACR BI-RADS Atlas ${ }^{\circledR}$ 5th Edition acr.org/birads. 
28. Wojciech P. Olszewski, Jacek Gałecki, Multinodular breast tumours - new pathomorphological criteria for the classification of multiple unilateral breast tumours . Journal of Oncology 2012, volume 62 , number $5,371-375$

29. Nathan J. Coombs, John Boyages. Multifocal and Multicentric Breast Cancer: Does Each Focus Matter? Journal of ClinicalOncology, Volume 23, Issue 30 , October 20, 2005

30. Alessandro Neri, Daniele Marrelli, TizianaMegha. Clinical significance of multifocal and multicentric breast cancers and choice of surgical treatment: a retrospective study on a series of 1158 cases" BMC Surgery volume15, Article number: 1 (2015)

31. Tibor Tot, Maria Gere, Syster Hofmeyer et al. The subgross morphology of breast carcinomas: a single-institution series of 2033 consecutive cases documented in large-format histology slides 2020 Mar;476(3):373-381. doi: 10.1007/s00428-019-02641-6. Epub 2019 Aug 13.

32. Available from: sisbreast.org

33. Anna Bozzini, Giuseppe Renne, Lorenza Meneghetti, et al. Sensitivity of imaging for multifocalmulticentric breast carcinoma BCM Cancer. 01.12.2008 | Research article | Ausgabe 1/2008

34. Goldberg $M$, Whelan T.J. Accelerated Partial Breast Irradiation (APBI): Where Are We Now?. Curr Breast Cancer Rep 2020 Oct 18;1-10

35. Kirby A.M. Updated ASTRO guidelines on accelerated partial breast irradiation (APBI): to whom can be offer APBI outside a clinical trial?; Br J Radiol, 2018, May; 91(1085):20170565.

36. Vicini FA, Cecchini RS, White JR Long -term primary results of accelerated partial breast irradiation after breast-conserving surgery for early -stage breast cancer: a randomised, phase 3 , equivalence trial, Lancet. 2019 Dec 14;394(10215):2155-2164

37. Fiona J. Gilbert. Breast cancer screening in high risk women Oct 15;13(20):6144-52.doi: 10.1158/1078-0432.CCR-07-1270. Europe PCM

38. Christopher C Riedl, , Daniel Flöry. Magnetic Resonance Imaging of the Breast Improves Detection of Invasive Cancer, Preinvasive Cancer, and Premalignant Lesions During Surveillance of Women at High Risk for Breast Cancer Clinical Cancer Research:10.1158/1078-0432.CCR-071270 Published October 2007

39. Chiara lacconi, MD Lanie Galman, MD Junting Zheng. Multicentric cancer Detected at Breast Mr imaging and not at Mammography:Important or Not Radiology - Published Online:Nov 25 2015https://doi.org/10.1148/radiol.2015150796

40. Francesco Sardanelli, Franca Podo, Filippo Santoro.High Breast Cancer Risk Italian 1 (HIBCRIT-1) Study Multicenter Surveillance of Women at High Genetic Breast Cancer Risk Using Mammography, Ultrasonography, and Contrast-Enhanced Magnetic Resonance Imaging (The High Breast Cancer Risk Italian 1 Study): Final Results Investigative Radiology. 46(2):94-105, FEBRUARY 2011 DOI: 10.1097/RLI.0b013e3181f3fcdf

41. França LKL, Bitencourt AGV, Makdissi FBA et al. Impact of breast magnetic resonance imaging on the locoregional staging and management of breast cancer. Radiol Bras. 2019;52(4):211-216. doi:10.1590/0100-3984.2018.0064 
42. Selvi V, Nori J, Meattini I, et al. Role of Magnetic Resonance Imaging in the Preoperative Staging and Work-Up of Patients Affected by Invasive Lobular Carcinoma or Invasive Ductolobular Carcinoma [published correction appears in Biomed Res Int. 2018 Sep

6;2018:9056239. Di Benedetto D [corrected to De Benedetto D]]. Biomed Res Int. 2018;2018:1569060. Published 2018 Jun 26. doi:10.1155/2018/1569060

43. Turnbull L, Brown S, Harvey I, et al. Comparative effectiveness of MRI in breast cancer (COMICE) trial: a randomised controlled trial. Lancet. 2010;375:563-71 [Links]

44. Peters NH, Van Esser S, Van den Bosch MA, et al. Preoperative MRI and surgical management in patients with nonpalpable breast cancer: the MONRT - randomised controlled trial. Eur $\mathrm{J}$ Cancer. 2011;47:879-86. [Links]

45. Francesco Sardanelli. Magnetic Resonance Imagnig of the Brest : recommendations from the EUSOMA Working Group Eur J Cancer 2010 May;46(8):1296-316.

46. Xing, Dong BS*; Lv, Yongbin MSc*. Diagnostic Value of Contrast-Enhanced Spectral Mammography in Comparison to Magnetic Resonance Imaging in Breast Lesions Journal of Computer Assisted Tomography: March/April 2019 - Volume 43 - Issue 2 - pp. 245-251

47. Andrzej Lorek, Katarzyna Steinhof-Radwańska, Anna Barczyk-Gutkowska et al Retrospective Comparison of Contrast-Enhanced Spectral Mammography with Digital Mammography in Assessing Tumor Size in 668 Cases of Breast Cancer Med Sci Monit 2020; 26:e926977 DOI:

10.12659/MSM.926977

\section{Figures}

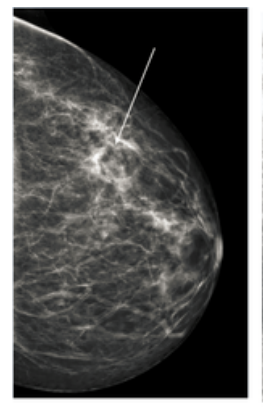

A

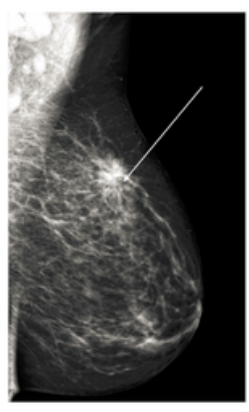

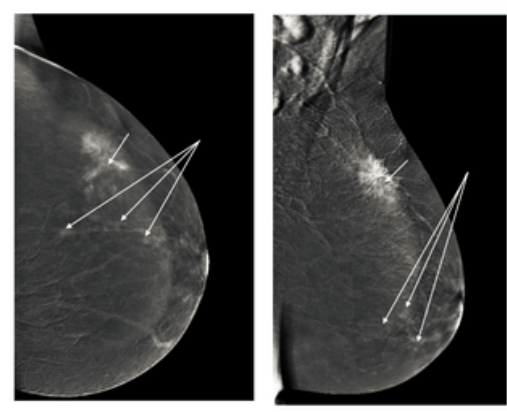

B
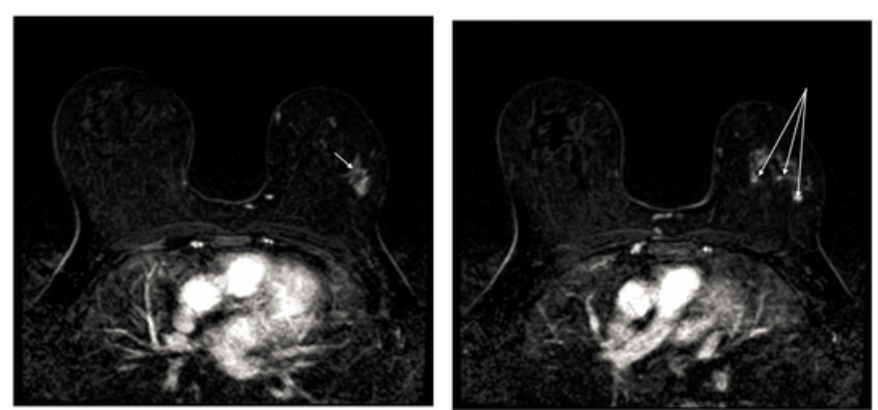

C

Figure 1

a. MAMMOGRAPHY (MG) CRANIOCAUDAL (CC) AND MEDIOLATERAL OBLIQUE (MLO) VIEWS PATHOLOGICAL MASS IN THE LEFT BREAST, IN THE SUPERIOR-OUTER QUADRANT (WHITE ARROWS), HP-CA LOBULARE G II BI-RADS 6 b. CESM (CONTRAST-ENHANCED SPECTRAL MAMMOGRAPHY), SUBTRACTION IMAGES, CRANIOCAUDAL (CC) AND MEDIOLATERAL OBLIQUE (MLO) - CESM REVEALS IRREGULAR MASS WITH HETEROGENEOUS ENHANCEMENT AND WITH LONG SPICULATIONS BI-RADS 6 (SHORT WHITE ARROW). NUMEROUS ENHANCED SMALL FOCI ARE NOTED IN LEFT BREAST BI-RADS 4 
(WHITE ARROWS). c. MRI (MAGNETIC RESONANCE IMAGING) SUBTRACTION IMAGE 2 MINUTES AFTER CONTRAST INJECTION IRREGULAR MASS WITH HETEROGENEOUS ENHANCEMENT BI-RADS 6 (SHORT WHITE ARROW) WITH NUMEROUS FOCI OF CONTRAST UPTAKE SHOWING MULTICENTRIC CANCER BIRADS 4 (WHITE ARROWS)

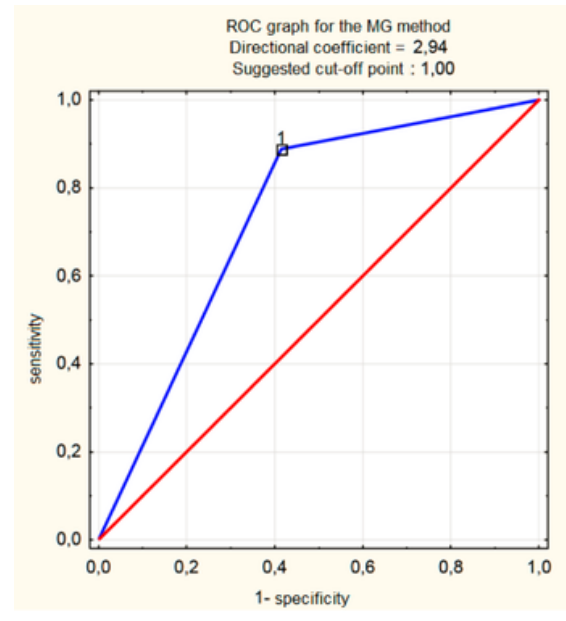

A

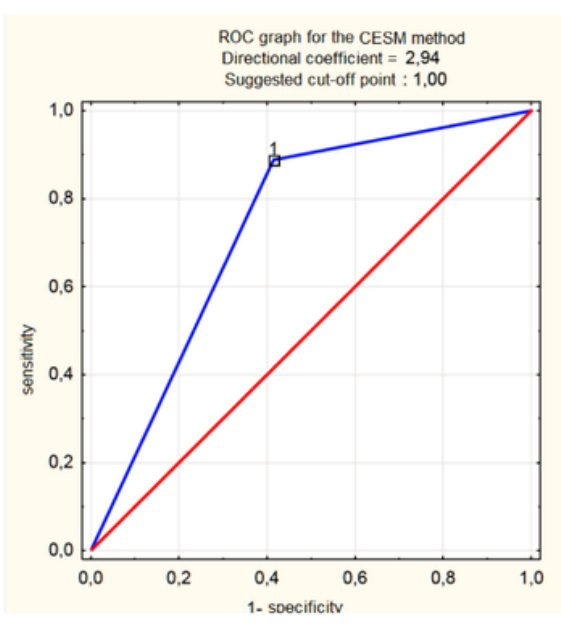

B

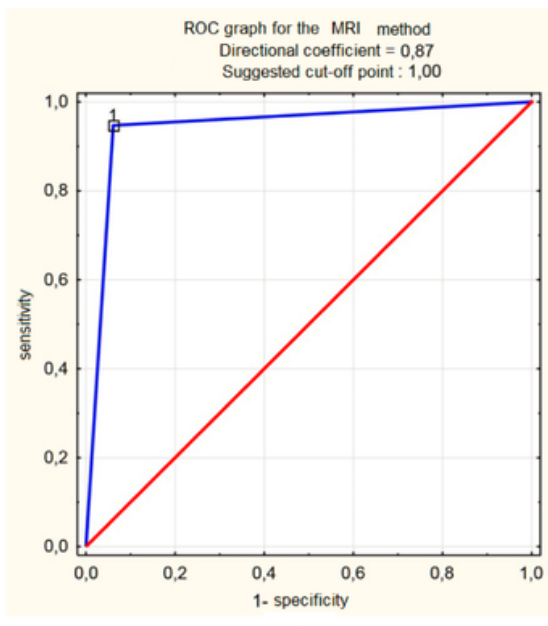

C

\section{Figure 2}

a. THE VALUE OF THE AUC FIELD OBTAINED IN THIS METHOD WAS 0.737 WITH A STANDARD ERROR OF 0.063 AND P<0.05. b. THE VALUE OF THE AUC FIELD OBTAINED IN THIS METHOD WAS 0.874 WITH A STANDARD ERROR OF 0.046 AND P<0.05. c. THE VALUE OF THE AUC FIELD OBTAINED IN THIS METHOD WAS 0.943 WITH A STANDARD ERROR OF 0.032 AND $P<0.05$. 